\title{
Medium-Term Forecast of Government Spending on the Unemployment Social Protection System in Russia in the Conditions of Economic Recession
}

\author{
M. E. Baskakova ${ }^{a, *}$, V. N. Baskakov ${ }^{b}$, and E. A. Yanenko ${ }^{b}$ \\ ${ }^{a}$ Institute of Economics, Russian Academy of Sciences, Moscow, 117418 Russia \\ ${ }^{b}$ International Actuarial Advisory Company, Moscow, 125284 Russia \\ *e-mail: baskakovame@mail.ru \\ Received March 31, 2021; revised May 31, 2021; accepted September 22, 2021
}

\begin{abstract}
A simulation model of the Russian unemployment social protection system is developed and used to study the impact of the economic crisis caused by the COVID-19 pandemic, demographic processes, and the increase in retirement age on federal spending on unemployment benefits. Trends of overall and registered unemployment across various socio-demographic groups in 1992-2020 are analyzed, with special attention paid to periods of economic recession and recovery. The identified patterns are used to develop modeling scenarios. Calculations show that in the unfavorable scenario government spending on unemployment benefits will increase many times. As a possible solution to the problem, it is proposed to convert the unemployment social protection system to insurance principles. The time frame in which reforming the system would be less expensive for the federal budget is defined.
\end{abstract}

Keywords: economic crisis, COVID-19 pandemic, unemployment rate, simulation model, scenarios, financial flows, federal budget, unemployment benefits, benefit duration

DOI: $10.1134 / \mathrm{S} 107570072201004 \mathrm{X}$

Introduction. In order to combat the spread of COVID-19, most states of the world have been forced to introduce economic, administrative, and organizational measures that reduce territorial movements of their citizens and restrict certain types of economic activity. This has led to increased unemployment in national labor markets. Between March and May of 2020, the unemployment rate in the United States increased from 2.1 to $17.1 \%$ [1], in the EU, from 6.6 to $7.0 \%,{ }^{1}$ and in Russia, from 4.7 to $6.1 \% .^{2}$

During the first wave of the pandemic, in order to offset the negative consequences of the sharp increase in unemployment and curb its further growth, some countries significantly increased spending on unemployment assistance, relaxing eligibility criteria and increasing benefit amounts [2].

By the time the second wave hit, the economies of a number of countries were unable to continue providing such assistance at the same level. Governments have begun reducing unemployment benefits, being more cautious about introducing new restrictions, and replacing some prohibitions with recommendations. Today, despite certain achievements in the fight

\footnotetext{
${ }^{1}$ Eurostat. https://ec.europa.eu/eurostat/databrowser/view/ une_rt_m/default/table?lang=en.

2 Rosstat. https://rosstat.gov.ru/compendium/document/13265.
}

against COVID-19, the duration of the presence of the infection in different countries and its impact on their economic development remains uncertain.

The Russian labor market has had to contend with additional risk factors: the gradual increase in retirement age, which started in 2019, and effects of demographic waves. Therefore, forecasting the number of the unemployed and the associated social protection spending, which affects the balance of the state budget, is of particular importance.

Research objective. The research objective is to obtain a medium-term scenario forecast of unemployment social protection spending in Russia in the conditions of labor market turbulence caused by the COVID-19 pandemic, the increase in retirement age, and demographic changes.

The core of the research is a comprehensive study that involves research of the socio-economic context of the labor market, development of a simulation model for forecasting financial flows of the unemployment social protection system and modeling scenarios, conducting forecast calculations, and analyzing their results.

Studies of that kind are a traditional part of analysis of financial flows in the pension system abroad and in Russia [3, 4]. Studies of the unemployment social pro- 
tection (insurance) system in such a formulation are not found in Russian literature and are rarely found in foreign literature [5], although various aspects of unemployment are analyzed in numerous theoretical works and empirical studies.

Thus, the ILO conducts international monitoring of unemployment. ${ }^{3}$ Analysis of unemployment during periods of economic downturn can be found in $[6,7]$. Features of unemployment in Russia are considered in $[8,9]$. Challenges of the labor market associated with digitalization are discussed in [10].

Forecasting the unemployment rate is a common research topic; the methods vary widely.

In the United States, such forecasts are based on forecasts from the Federal Reserve Greenbook and by professional forecasters (SPF) [11]. In addition, forecasts also use the empirical relationship between the GDP growth rate and the unemployment rate [12], called Okun's law, and its modifications [13].

Econometric models-linear and nonlinear parametric, time series models-are also used to forecast the unemployment rate $[14,15]$. The problem of that approach is the need to justify the choice of the appropriate parametric family of models. An alternative is using nonparametric methods [16], but in that case the difficulty lies in constructing a forecast with explanatory variables with values that go beyond the limits of available statistics.

In [17], it is proposed to solve these problems by using neural network-based models, whose advantages and disadvantages are well-known [18] and are not tied to any specific applied problems. The advantages include the ability to find solutions without knowing the patterns, resistance to noise in the input data, and adaptability to changes in context; the disadvantages include the inability to solve computational problems.

Unemployment rate forecasting by econometric models generally does not incorporate demographic shifts in the gender and age distribution of the population that affect the labor force participation rate [19], and, consequently, the unemployment rate, into the analysis. That may prove critical even in medium-term forecasting of financial flows of the unemployment protection system.

Analysis of unemployment duration is a less popular topic, but it is also important for forecasting spending on unemployment protection. Unemployment duration is usually estimated based on data of labor force surveys, in which it appears censored. Therefore, its distribution function is constructed using survival analysis methods [20].

Current unemployment social protection system. The current Russian unemployment social protection system is regulated by the Federal Law No. 1032-1 of

\footnotetext{
${ }^{3}$ Ilostat. https://ilostat.ilo.org/data/.
}

April 19, 1991, On the Employment of the Population in the Russian Federation, which defines the unemployed as employable citizens who do not currently have a paid job, are registered with employment agencies, are seeking a job, and are available for work. The unemployed status is assigned to such citizens 10 days after submission of the relevant documents, if they were not provided with a suitable job within this period. Citizens under the age of 16 or receiving old age pension are not recognized as unemployed.

The current system theoretically covers $100 \%$ of the employable population. The unemployed status comes with the right to unemployment benefits. Unemployed persons who have worked for at least 26 weeks during the 12 months preceding unemployment receive $75 \%$ of their previous average monthly wages for the first three months, then $60 \%$ for the following three months. The benefit amount has a lower and an upper limit. In 2021, the maximum benefit for the first three months of unemployment was set at 12130 rubles, for the following three months, at 5000 rubles (for citizens of preretirement age, the maximum benefit amount does not depend on benefit duration and is always 12130 rubles). The minimum benefit amount is 1500 rubles. Citizens who have never been employed before, have not been employed in over a year, have been employed for less than 26 weeks over the past year, or were dismissed from their previous job for breaches of discipline are only entitled to the minimum amount of benefits.

Key functional parameters of the model. A simulation model (toolkit) for predicting financial flows of the unemployment social protection system in Russia under different scenarios of socioeconomic development of the country and with different values of the parameters of benefit eligibility, size, duration, etc., has been created in Excel using VBA.

The toolkit is based on the social cohort approach $[4,21]$, which allows adjusting for demographic effects and the increase in retirement age on the number and age distribution of the unemployed, and, consequently, on financial flows of the studied system.

The toolkit includes three functional units (sociodemographic unit, financial unit, and labor market indicators calculation unit) and a system for entering scenario parameters and publishing reports with forecast calculation results.

The socio-demographic unit forecasts the age and gender distribution of the population using the builtin model [22] or an external demographic forecast. Using scenario assumptions and empirical age and gender profiles of the labor force, people employed in the economy, the unemployed according to the ILO definition and the registered unemployed, the population is divided into corresponding socio-demographic groups. The current process of raising the retirement age in Russia from 60 to 65 years for men and from 55 to 60 years for women can be represented by modifying 
the gender and age profile of the labor force. All calculations are differentiated by gender, age, and place of residence (urban/rural) of labor force participants. A separate calculation cell is created for each group.

The socio-demographic unit outputs time series of the sizes of these socio-demographic population groups. Only cohort sizes in the reference year of the forecast and forecast and scenario values of the overall unemployment rate are exogenous.

The labor market indicators calculation unit enables a deeper differentiation of the unemployed, identifying subgroups that are eligible for unemployment benefits of varying amount and duration by law or on other grounds. That is represented as a matrix of qualification conditions, which includes distributions of the unemployed by previous employment status, reasons for unemployment, pension insurance record, and citizenship and is used as the basis for distribution of the unemployed of each calculation group into subgroups.

Let us consider an example subgroup: male Russian citizens, 20 years old, living in a city, had been in paid employment for over three years with a salary of 90 thousand rubles per month, were dismissed for personal reasons. By law, they can claim benefits of the maximum amount and duration. But if they had had less than a year of work experience (that would be a different group), they would only be eligible to receive the minimum amount of benefits for no longer than three months.

To assess the duration of unemployment $u$, the toolkit includes a regression model, which uses the PROC HPSEVERITY ${ }^{4}$ SAS procedure to model the influence of the exogenous variables age $x$, gender $s$, and place of residence $r$ of the unemployed person on its distribution

$$
F(u ; \theta, \tau)=\left\{\begin{array}{l}
0, u<0 \\
1-\exp \left(-\left(\frac{u}{\theta}\right)^{\tau}\right), u \geq 0,
\end{array}\right.
$$

where $\theta=\theta_{0} \exp \left(\beta_{1} x+\beta_{2} x^{2}+\beta_{3} x^{3}+\beta_{4} s+\beta_{5} r\right)$ is the scale parameter, $\theta_{0}$ is its reference value, $\tau$ is the shape parameter, and $\beta_{1}, \ldots, \beta_{5}$ are regression coefficients.

The toolkit can be used to forecast the total number of citizens who have become unemployed this year, including rotation (hereinafter the newly unemployed), as well as the registered unemployed and recipients of unemployment benefits. The death rate of the unemployed is assumed to be the same as the death rate of the entire population, and the impact of migration is not considered.

\footnotetext{
${ }^{4}$ https://support.sas.com/documentation/cdl/en/etshpug/66412/ HTML/default/viewer.htm\#etshpug_hpseverity_details14.htm.
}

Due to the lack of necessary information, the modeling does not reflect that changes in the unemployment rate may be accompanied by changes in its duration. However, as empirical data accumulates, a corresponding model can be developed and added to the toolkit.

The financial unit forecasts wages of employees depending on gender and age ${ }^{5}$ and coordinates that with macroeconomic forecasts of average wages and estimated number of people employed. Then the unit calculates the average amount of unemployment benefits, adjusted for the lower and upper limits, and total spending on benefits as the product of their amount, expected duration, and number of recipients. Additional expenses on benefits for minors in the care of unemployed citizens and administrative expenses are also included in the calculations.

The toolkit operates with information on the size of the labor force, number of persons employed, number of persons unemployed according to the ILO definition, as well as their distribution by gender, age, and other parameters in the reference year of the forecast. The main source of these data is the Rosstat Labor Force Survey (LFS), conducted since 1992. The LFS data represent a cross-section of the state of the labor market at the time of the survey, therefore, the collected information about all processes' development over time is usually censored and/or truncated. For this reason, a number of indicators are calculated using additional information or assumptions that compensate for the lack of data. The auxiliary sources of information are state and departmental statistical reports, including data from government employment services.

The toolkit uses two types of scenario parameters. Scenario parameters of the first type determine the design of the system, including its coverage, the amount and duration of unemployment benefits, the retirement age, financing sources for the system, etc. The study used the parameters of the current system of unemployment social protection in Russia. Scenario parameters of the second type are represented by a set of time series that determine the population size differentially by age and gender, key macroeconomic indicators, and parameters of the unemployment rate. The study used official demographic forecasts by Rosstat (Fig. 1) and macroeconomic forecasts of the Ministry of Economic Development of the Russian

\footnotetext{
${ }^{5}$ The study uses the database of the International Actuarial Advisory Company (IAAC), which has been up since 2007 and is updated annually with information about gender, age, work experience, wages, and other indicators about employees received from HR departments of a number of medium and large Russian enterprises from different industries. The state provides similar statistical reports (https://rosstat.gov.ru/compendium/document/60671), but those contain information on wages of employees of organizations by staff categories, professional and other groups of employees in an aggregated form and therefore cannot be used for the purposes of this study.
} 


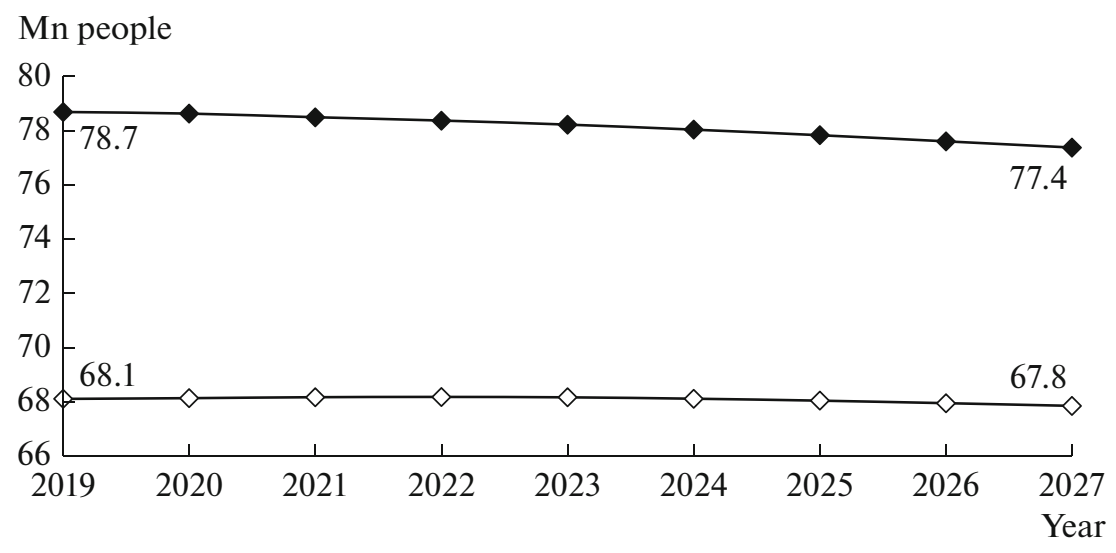

Fig. 1. Forecasted population size, average of the Rosstat forecast, mn people: $-\diamond-$ men; $-\diamond-$ women.

Federation (Table 1). Scenarios of unemployment rate changes in the medium term were developed by experts based on the historical experience of labor market transformations during periods of economic recession and subsequent recovery.

The report publication system includes over 100 time series with forecast calculation results, including forecasts of the gender and age distribution of the labor force, number of people employed, number of the unemployed by the ILO definition and the registered unemployed, spending on unemployment benefits, average amount and duration of benefits, total spending on the unemployment social protection system, and other indicators. The financial performance of the system is expressed in real/nominal terms and as shares of the salary budget and the GDP.

Scenarios of unemployment rate changes. The main variable scenario parameter was the overall unemployment rate (unemployment calculated according to the ILO methodology), the values of which have been relatively low over all years of observation. In the 1990s, they were lower than in most Eastern European countries [8], and over the last 20 years they have stayed below the global average. ${ }^{6}$ In 1992-2019, this level ranged from $13.3 \%$ in 1998 to $4.6 \%$ in 2019.

Since 1992, the Russian economy has gone through four crisis periods accompanied by fluctuations in the unemployment rate. Until recently, each subsequent crisis was accompanied by increasingly smaller rises in overall unemployment. In the first crisis period, from the beginning of the radical economic reforms to the depression of 1998, the unemployment rate increased to $13.3 \%$, the highest level in the history of observations (Fig. 2). The second period, 2008-2009, a consequence of the global economic crisis, brought this rate to a new local maximum, $8.4 \%$, in 2009. The third period, 2014-2015, the result of the "sanctions war," barely affected this indicator at all; in 2015 it

\footnotetext{
${ }^{6}$ Ilostat. https://ilostat.ilo.org/data/.
}

was at $5.5 \%$. The economic crisis brought by the pandemic led to an increase in the average annual rate to $5.8 \%$ in 2020 .

Reducing volatility of the unemployment rate during crisis periods was achieved primarily by the state policy of stabilizing the labor market and supporting the unemployed, adjusted for the specifics of each crisis.

The volume of financial flows of the unemployment protection system depends on the scale and rate of registered unemployment and the differences between these indicators and the corresponding indicators of overall unemployment. Significant discrepancy between these indicators is characteristic of the Russian labor market, the reasons for which are described in [23]. The largest discrepancy was observed in 2000 , when the number of the registered unemployed amounted to $14.7 \%$ of the overall unemployed. Since the crisis of 2008-2009, when the state first began providing large scale support to citizens who have lost their jobs, the trend has been for the share of the registered unemployed in their total number to increase during crisis periods. Thus, in 2008 this share was $28.7 \%$, in $2020,55.8 \%$.

Another distinctive feature of Russian unemployment is the persistent duality of its gender asymmetry. In all years of observation except 2004 and 2020, the rate and scale of overall unemployment for women were less than the corresponding indicators for men, while the ratio of these indicators for registered unemployment was usually the opposite.

Youth unemployment also has some specific features. As in most countries, the youth unemployment rate in Russia is many times higher than the unemployment rate of the older population (according to ILO estimates, ${ }^{7}$ in 2019 this rate was $15.2 \%$ among $15-$ 24 year olds, $4 \%$ among $25-54$ year olds, $2.9 \%$ among

\footnotetext{
${ }^{7}$ ILO. https://www.ilo.org/shinyapps/bulkexplorer26/?lang=en\& segment=indica-tor\&id=UNE_DEAP_SEX_AGE_RT_A.
} 
Table 1. Basic macroeconomic forecast of the Ministry of Economic Development of the Russian Federation

\begin{tabular}{l|c|c|c|c|c}
\hline \multicolumn{1}{c|}{ Indicator } & 2019 & 2020 & 2021 & 2022 & 2023 \\
\hline Inflation & 104.5 & 103.2 & 103.6 & 103.9 & 104.0 \\
Payroll budget, bn rubles & 25209 & 26055 & 27890 & 29815 & 31904 \\
Average salary, rubles & 47867 & 50131 & 53096 & 56404 & 60157 \\
GDP, bn rubles & 110046 & 106974 & 115533 & 124223 & 132822 \\
\hline
\end{tabular}

55-64 year olds, and $2.8 \%$ for $65+$ year olds). The youth unemployment rate in Russia is not significantly higher than the global average (13.5\%) and is close to the average for the G20 countries $(16.3 \%)^{8}$. But the scale of youth unemployment in Russia relative to the total number of young people is small, since most young people are receiving education, which is why their economic activity is very limited (in 2019 its level was $32.2 \%$, which is significantly lower than the global average of $41.2 \%$ ).

Over the last fifteen years, the unemployment rate of the rural population has significantly exceeded the unemployment rate of the urban population. The minimum ratio of these indicators was observed in 2009, when the unemployment rate of rural residents was only 1.5 -fold higher than the corresponding indicator of urban residents; the maximum was observed in 2006, when the difference was 2.2-fold. The general trend is that the differences in the values of these indicators are smaller in crisis years and larger in years of economic growth. This is most likely due to the fact that during crisis years rural residents can more easily turn to subsistence farming for income generation, which in the Rosstat methodology is considered employment.

The reveled patterns of unemployment rate changes over time were used to develop three scenarios of changes in the unemployment rate in the medium term ${ }^{9}$.

The first is the status quo scenario, used as the basis for calculating increases in spending on the unemployment social protection system during periods of economic downturn, in which the scenario parameters of unemployment are assumed to remain at the level of the end of 2019 throughout all forecast years.

The second is the expected scenario, in which the unemployment rate is assumed to continue to decline in the coming years (as it has started to decline in

\footnotetext{
8 Ilostat: https://ilostat.ilo.org/data/.

${ }^{9}$ In the toolkit, the overall unemployment rate is formally a calculated indicator. That is because in each forecast year, the values of unemployment rate increases compared to the reference year are set exogenously for all gender and age cohorts of the labor force. Therefore, the overall unemployment rate additionally depends on the demographic forecast of the gender and age distribution of the population and the ongoing retirement age changes that determine the gender and age structure of the labor force.
}

October 2020) and is expected to reach its precrisis values by the end of 2023 .

The third is the pessimistic scenario, which assumes another increase in the unemployment rate up to $5.65 \%$ by 2022 , caused by the third wave of the pandemic; recovery is expected be complete only by 2027.

A diagram of changes in the unemployment rate for each scenario is presented in Fig. 3. Differentiation of scenario unemployment rates by gender, age, and place of residence is carried out using a built-in model based on the identified parameter ratios.

Some results of scenario calculations are given in Table 2. Due to scope limitations of the article, they are differentiated only by place of residence of labor force participants and by forecast year. These indicators were chosen because gender differences in unemployment rates in Russia are small, while place of residence differences are significant.

Table 2 shows that the number of employed people will consistently decrease. Over 2019-2027, it will decrease by $0.94 \%$. If we abstract from the current crisis (the status quo scenario), the number of unemployed people by the ILO definition will also decrease by $1.59 \%$ over these years. The expected and pessimistic scenarios assume that the maximum increase in the unemployment rate during this crisis has already occurred in 2020, when the number of the unemployed amounted to 4389 thousand people.

The third wave of the pandemic is expected only in the pessimistic scenario, in which a local increase in the number of the unemployed to 4205 thousand people occurs in 2022, and precrisis levels return by 2027 . In the expected scenario, this occurs in 2024.

The noted trends are significantly influenced by the upcoming demographic changes and, in part, the increase in retirement age. Their impact on unemployment social protection will be discussed further.

The next forecast indicator is the number of the newly unemployed. Calculations have shown that that number is $1.58-1.63$-fold larger than the number of the ILO unemployed throughout all forecast years.

Figure 4 presents the calculation of the average unemployment benefit duration depending on place of residence and age ${ }^{10}$ of the unemployed person with

\footnotetext{
${ }^{10}$ Calculations have shown that the effect of the unemployed person's gender on this indicator is negligibly small, so the dependences in Fig. 4 are valid for both men and women.
} 


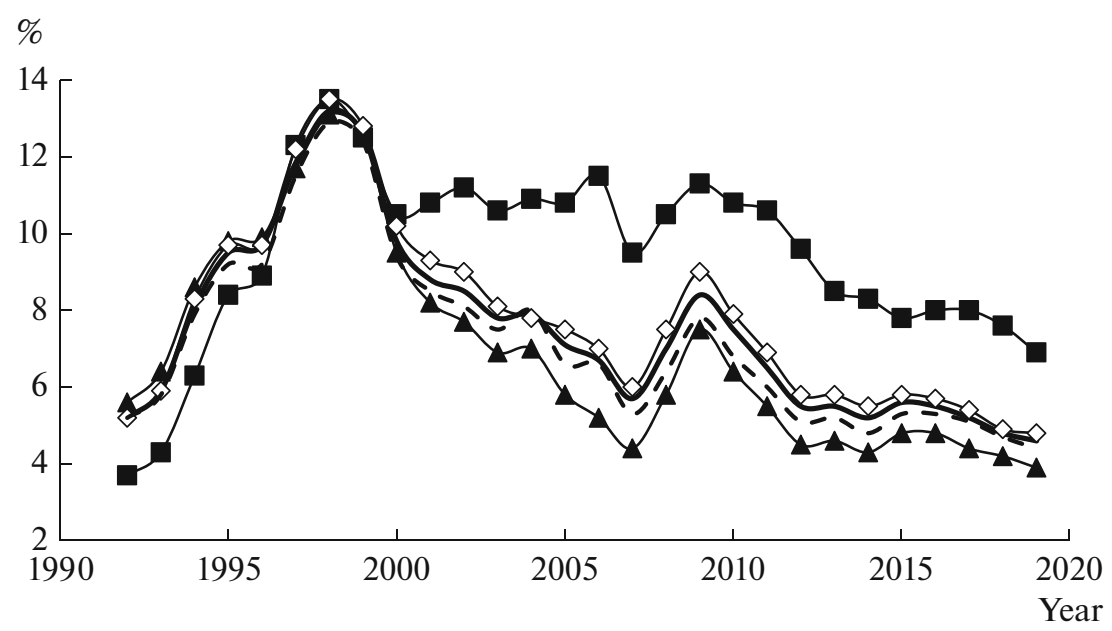

Fig. 2. Unemployment rate over time, differentiated by gender and place of residence of labor force participants: $-\mathbf{\Delta}-$ urban; $-\mathbf{\square -}$ rural; - entire population; - $\diamond-$ men; --- women.

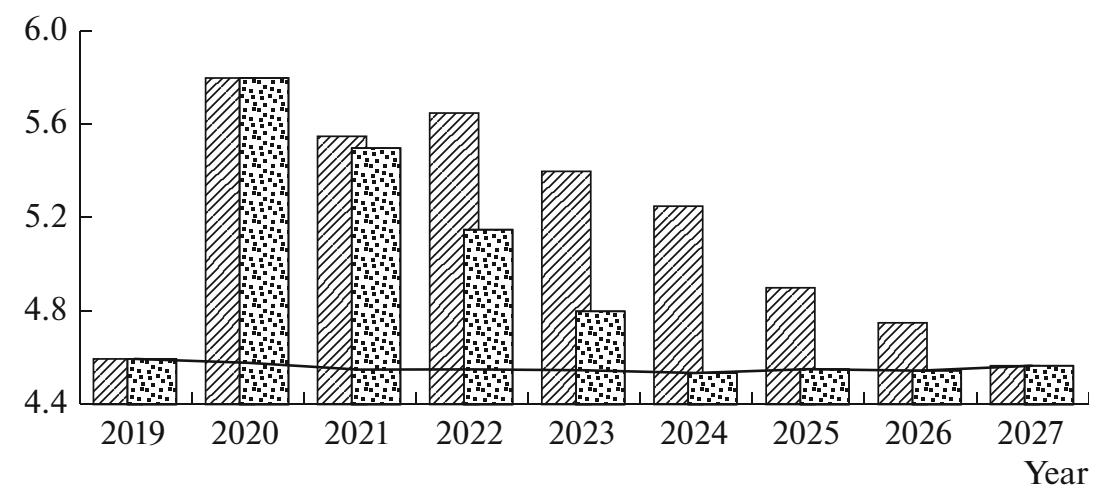

Fig. 3. Scenarios of changes in the unemployment rate: 0 pessimistic;

an upper limit of six months. It follows from the data that the factor that influences unemployment duration the most is age: for young people under 30, finding a new job takes on average less than 3.5 months, while for people of retirement age it takes more than 5.0 months. Living in rural areas increases job search duration by $4-43 \%$, while the gender of the unemployed person has very little effect on the indicator.

Federal budget spending on unemployment benefits can be estimated as the product of the number of benefit recipients and the average benefit amount and duration. Figure 5 presents budget spending on benefits in the Russian Federation over time across different scenarios of changes in the unemployment rate.

Calculations show that for 2019-2027, total federal budget spending on unemployment benefits in the status quo, expected, and pessimistic scenarios are equal to $466.0,1173.6$, and 1463.4 bn rubles respectively. The maximum difference in spending between the expected scenario and the status quo scenario is observed in 2020, when it amounts to $405 \%$; between the pessimistic scenario and the status quo scenario in 2022 , it is $481 \%$.

Federal budget spending at the end of the recovery period of the overall unemployment rate, which is assumed to occur in 2024 in the expected scenario and in 2027 in the pessimistic scenario, exceed the spending in the status quo scenario more than 2-fold. That is due to the fact that during the pandemic the state has demonstrated its intention to support taxpaying enterprises and employees. It is natural to assume that the signal will be received and after the crisis the registered unemployment rate will remain at $1.48 \%$ rather than return to its initial level of $0.97 \%$.

It has been noted that spending on the unemployment protection system is also influenced by demographic changes and the increase in retirement age. The reasons for this influence are illustrated in Fig. 6, which presents the gender and age distributions of the labor force in 2019 and 2027. It follows from the graphs 
Table 2. Results of scenario calculations

\begin{tabular}{|c|c|c|c|c|c|c|c|c|c|c|c|}
\hline \multirow{3}{*}{ Indicator } & \multirow{3}{*}{ Scenario } & \multicolumn{10}{|c|}{ Forecast year/Place of residence } \\
\hline & & \multicolumn{2}{|c|}{2019} & \multicolumn{2}{|c|}{2021} & \multicolumn{2}{|c|}{2023} & \multicolumn{2}{|c|}{2025} & \multicolumn{2}{|c|}{2027} \\
\hline & & urban & rural & urban & rural & urban & rural & urban & rural & urban & rural \\
\hline \multirow{3}{*}{$\begin{array}{l}\text { Employed, } \\
\text { th. people }\end{array}$} & Status quo & 55886 & 16047 & 55682 & 15975 & 55150 & 15834 & 55130 & 15870 & 55285 & 15975 \\
\hline & Expected & & & 55212 & 15730 & 55026 & 15769 & & & & \\
\hline & Pessimistic & & & 55187 & 15718 & 54733 & 15616 & 54960 & 15781 & & \\
\hline \multirow{3}{*}{$\begin{array}{l}\text { ILO unemployed, th. } \\
\text { people }\end{array}$} & Status quo & 2284 & 1181 & 2247 & 1168 & 2222 & 1159 & 2225 & 1161 & 2242 & 1168 \\
\hline & Expected & & & 2716 & 1413 & 2346 & 1224 & & & & \\
\hline & Pessimistic & & & 2741 & 1425 & 2639 & 1376 & 2395 & 1250 & & \\
\hline \multirow{3}{*}{$\begin{array}{l}\text { ILO unemployment } \\
\text { rate, } \%\end{array}$} & Status quo & 3.93 & 6.85 & 3.88 & 6.82 & 3.87 & 6.82 & 3.88 & 6.81 & 3.90 & 6.81 \\
\hline & Expected & & & 4.69 & 8.24 & 4.09 & 7.20 & & & & \\
\hline & Pessimistic & & & 4.73 & 8.32 & 4.60 & 8.10 & 4.18 & 7.34 & & \\
\hline \multirow{3}{*}{$\begin{array}{l}\text { ILO newly unem- } \\
\text { ployed, th. people }\end{array}$} & Status quo & 3836 & 1634 & 3795 & 1615 & 3797 & 1608 & 3848 & 1619 & 3923 & 1640 \\
\hline & Expected & & & 4588 & 1953 & 4008 & 1698 & & & & \\
\hline & Pessimistic & & & 4629 & 1971 & 4509 & 1910 & 4143 & 1744 & & \\
\hline \multirow{3}{*}{$\begin{array}{l}\text { Registered unem- } \\
\text { ployed, th. people }\end{array}$} & Status quo & 482 & 252 & 475 & 250 & 473 & 250 & 476 & 252 & 481 & 254 \\
\hline & Expected & & & 1264 & 665 & 749 & 396 & 713 & 377 & 721 & 381 \\
\hline & Pessimistic & & & 1441 & 758 & 1273 & 673 & 777 & 411 & & \\
\hline \multirow{3}{*}{$\begin{array}{l}\text { Registered unem- } \\
\text { ployment rate, \% }\end{array}$} & Status quo & 0.83 & 1.46 & 0.82 & 1.46 & 0.82 & 1.47 & 0.83 & 1.48 & 0.84 & 1.48 \\
\hline & Expected & & & 2.18 & 3.88 & 1.30 & 2.33 & 1.24 & 2.22 & 1.25 & 2.22 \\
\hline & Pessimistic & & & 2.49 & 4.42 & 2.22 & 3.96 & 1.36 & 2.41 & & \\
\hline \multirow{3}{*}{$\begin{array}{l}\text { Unemployment ben- } \\
\text { efit recipients, th. } \\
\text { people }\end{array}$} & Status quo & 393 & 206 & 388 & 204 & 386 & 204 & 388 & 205 & 393 & 207 \\
\hline & Expected & & & 1032 & 543 & 611 & 323 & 583 & 308 & 589 & 311 \\
\hline & Pessimistic & & & 1177 & 619 & 1040 & 549 & 635 & 336 & & \\
\hline \multirow{3}{*}{$\begin{array}{l}\text { Budget spending on } \\
\text { unemployment bene- } \\
\text { fits, bn rubles }\end{array}$} & Status quo & 30.9 & 16.1 & 30.9 & 16.3 & 33.3 & 17.6 & 36.5 & 19.0 & 39.9 & 20.8 \\
\hline & Expected & & & 120.5 & 63.4 & 77.7 & 41.2 & 80.6 & 42.2 & 88.3 & 46.4 \\
\hline & Pessimistic & & & 137.4 & 72.2 & 132.1 & 70.0 & 87.8 & 46.0 & & \\
\hline
\end{tabular}

that demographic waves during this period will cause the number of labor force participants aged $60+$ is primarnumber of labor force participants aged 24-36 years to ily due to the increase in retirement age. sharply decrease, while the number of employed people aged 38-55 years will increase. The increased

Duration of benefits, months

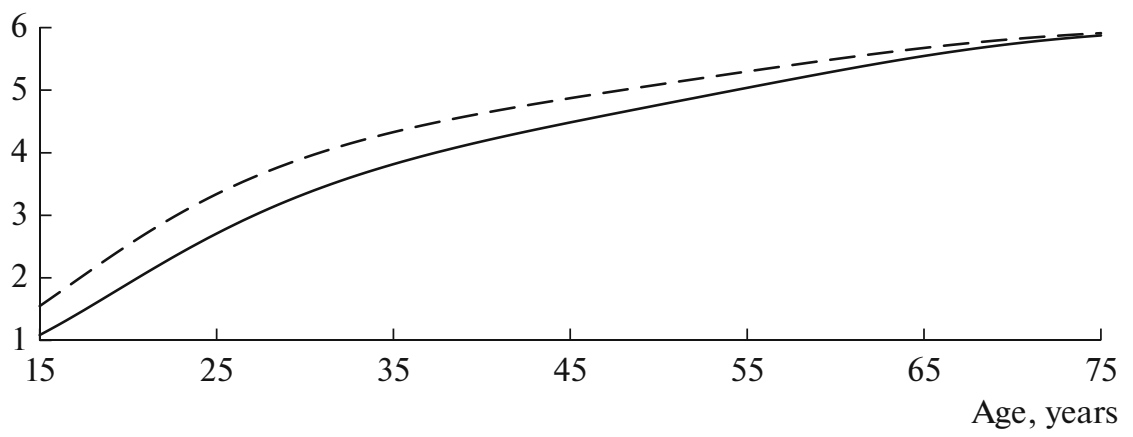

Fig. 4. Expected unemployment benefit duration:- urban; --- rural. 


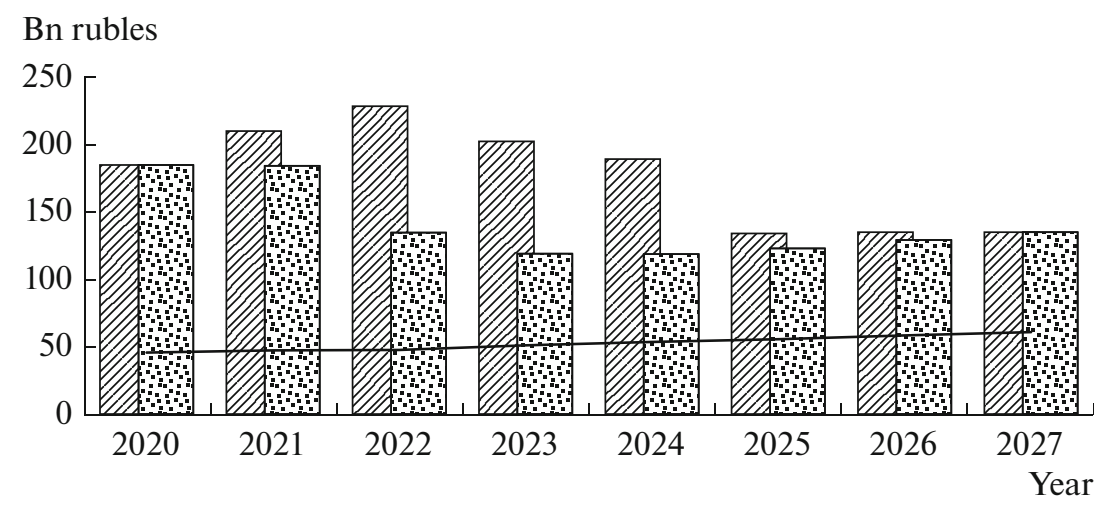

Fig. 5. Government spending on unemployment benefits over time across scenarios of changes in the unemployment rate: $\square$ pessimistic; $:$ : expected; - status quo.

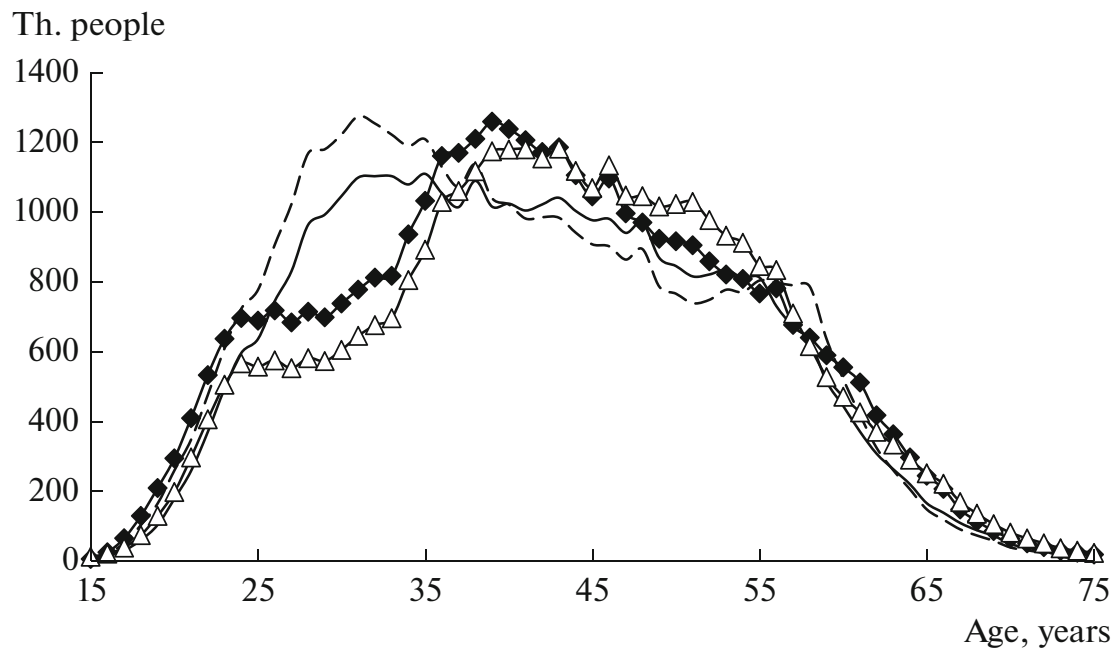

Fig. 6. Age and gender profiles of the labor force: men: $---2019 ;-\checkmark-2027$; women: $-2019 ;-\triangle-2027$.

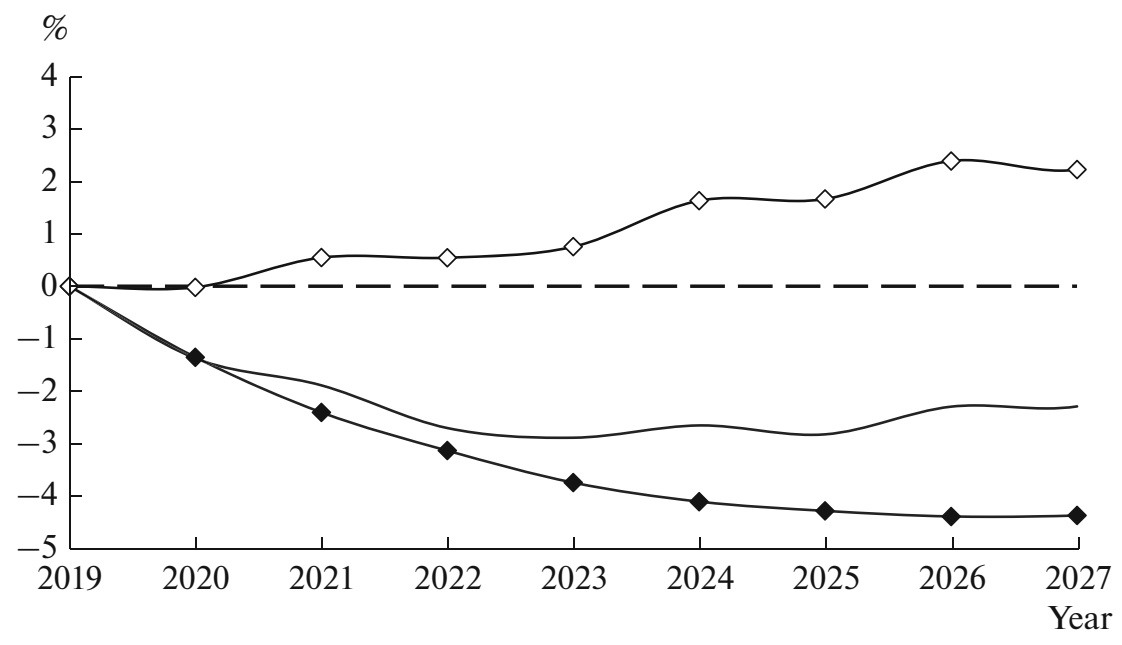

Fig. 7. Relative contribution of demographic changes (D) and the increase in retirement age (R) to federal spending on unemployment benefits: $(+)$ the parameter is included or $(-)$ not included in calculations: $-\mathrm{D}(+), \mathrm{R}(+) ;-\bullet-\mathrm{D}(+), \mathrm{R}(-) ;-\diamond-\mathrm{D}(-)$, $\mathrm{R}(+) ;---\mathrm{D}(-), \mathrm{R}(-)$. 
According to the calculations, under the expected scenario, due to the increase in retirement age, by 2027 the size of the labor force will increase by 3365 thousand people, the overall number of unemployed people by almost 100 thousand people, and the number of registered benefit-receiving unemployed people by only 18 thousand people. Budget spending on unemployment benefits associated with the increase in retirement age will amount to 3.06 bn rubles or $2.2 \%$ of total budget spending on these purposes (Fig. 7). The values of these indicators are largely determined by the longer unemployment duration for older citizens (see Fig. 4).

Demographic changes, on the contrary, contribute to a monotonic reduction in the number of the unemployed and in budget spending on unemployment benefits. By the end of the forecast period, budget spending associated with demographic changes will decrease by 6.03 bn rubles or $2.3 \%$ of total budget spending (Fig. 7). But after 2028, the situation will change: the number of young people in the labor force will gradually increase, which will lead to increases in the unemployment rate and government spending on unemployment.

Conclusions. It should be noted that the current unemployment protection policy in Russia does not meet the international requirements for such systems in terms of a number of parameters. That primarily concerns the low maximum amount of benefits. The practically "flat" amount of unemployment benefits disincentivizes the unemployed from registering with government employment agencies.

The problem may be solved by converting the unemployment protection system to insurance principles. The most favorable time for that is the next 6-7 years. Modeling has shown that in these years the demographic situation will contribute to a decrease in the unemployment rate. The process of increasing the retirement age and postcrisis recovery of the unemployment rate will also be completed within this period. Delaying the reform would result in an increase in federal budget spending on unemployment support, since after 2028 the demographic trend will change, leading to continuous increases in the unemployment rate over several years.

\section{REFERENCES}

1. R. Kochhar, Unemployment rose higher in three months of COVID-19 than it did in two years of the Great Recession, Pew Research Center. https://pewrsr.ch/2UADTTZ. Cited March 5, 2021.

2. A Quick Reference Guide to Common COVID-19 Policy Responses (International Labour Organization, Geneva, 2020). https://www.ilo.org/wcmsp5/groups/ public/-ed_dialogue/_act_emp/documents/publication/wcms_754728.pdf. Cited February 11, 2021.

3. The ILO Pension Model: A technical guide (International Labour Organization, Geneva, 2018). https://www.social-protection.org/gimi/RessourcePDF.action?id= 55195. Cited March 29, 2021.

4. V. N. Baskakov, A. L. Lelchuk, D. V. Pomazkin, and E. D. Khotulev, The Pension System: a Model for Russia and International Experience (Moscow Public Science Foundation, Moscow, 2003).

5. S. Dullien, A euro-area wide unemployment insurance as an automatic stabilizer: Who benefits and who pays? Paper prepared for the European Commission (DG EMPL), 2013. https://ec.europa.eu/social/BlobServlet?docId= 12510\&langId=en. Cited March 29, 2021.

6. A. G. Frank, "Unemployment and world crisis of economic policy," Econ. Polit. Weekly 18 (22), 969-976 (1983). http://www.jstor.org/stable/4372157. Cited March 30, 2021.

7. P. N. Junankar (Raja), The global economic crisis: long-term unemployment in the OECD, IZA Discussion Paper no. 6057, 2011. https://papers.ssrn.com/sol3/papers.cfm?abstract_id=1955397. Cited March 30, 2021.

8. R. I. Kapelyushnikov and N. T. Vishnevskaya, Phenomenon of Russian Unemployment: Dynamics, Structure, Specificity (Moscow Public Science Foundation, Moscow, 2003) [in Russian].

9. A. G. Korovkin and V. A. Shurpikov, "Quantitative evaluation of cyclical, frictional and structural unemployment in Russia," Nauchn. Tr. Inst. Narodokhoz. Prognoz., Ross. Akad. Nauk 2018, 163-176 (2018). https://doi.org/10.29003/m259.sp_ief_ras2018/163-176

10. S. Zemtsov, "New technologies, potential unemployment and 'nescience economy' during and after the 2020 eco-nomic crisis," Reg. Sci. Policy Pract., No. 12, 723-743 (2020).

https://doi.org/10.1111/rsp3.12286

11. H. Baghestani, "Federal Reserve versus private information: Who is the best unemployment rate predictor?,” J. Policy Model. 30, 101-110 (2008).

12. A. M. Okun, "Potential GNP: its measurement and significance" in Proceedings of the Business and Economic Statistics Section of the American Statistical Association ((American Statistical Association, Washington, DC, 1962), pp. 89-104.

13. A. Economou and I. N. Psarianos, "Revisiting Okun's law in European Union countries," J. Econ. Stud. 43 (2), 275-287 (2016).

https://doi.org/10.1108/JES-05-2013-0063

14. C. Floros, "Forecasting the UK unemployment rate: model comparisons," Int. J. Appl. Econometr. Quant. Stud. 2 (4), 57-72, (2005).

15. E. V. Semerikova and O. A. Demidova, "Using spatial econometric models for regional unemployment forecasting," Appl. Econometr. 43, 29-51 (2016).

16. A. Golan and J. M. Perloff, "Superior forecasts of the US unemployment rate using a nonparametric method,” Rev. Econ. Stat. 86 (1), 433-438 (2004). 
17. J. H. Stock and M. W. Watson, "Forecasting output and inflation: the role of asset prices," J. Econ. Lit. 41, 788-829 (2003).

18. A. I. Galushkin, Neural Networks: Foundations of Theory (Goryachaya Liniya-Telekom, Moscow, 2012) [in Russian].

19. P. Guerron-Quintana and M. Zhong, "Macroeconomic forecasting in times of crises" in Finance and Economics Discussion Series, 2017-018 (Board of Governors of the Federal Reserve System, Washington, 2017). https://doi.org/10.17016/FEDS.2017.018
20. T. Lancaster, "Econometric methods for the duration of unemployment," Econometrica 47 (4), 939-956 (1979).

21. The Republic of Moldova's Pension System: Actuary Expertise, Ed. by V. N. Baskakov (Asigurarea Sociala si de Pensionare, Moscow, 2007).

22. E. M. Andreev, "Component method in the analysis of life expectancy," Vestn. Stat., No. 9, 42-47 (1982)

23. R. I. Kapelyushnikov, Preprint No. WP3/2002, GU VShE (Higher School of Economics, Moscow, 2002).

Translated by A. Ovchinnikova 